\title{
Effect of Renal Sympathetic Nerve Stimulation on Proximal Water and Sodium Reabsorption
}

\author{
Elsa Bello-Reuss, Daniel L. Trevino, and Carl W. Gottschalk \\ From the Departments of Physiology and Medicine, University of North \\ Carolina School of Medicine, Chapel Hill, North Carolina 27514
}

\begin{abstract}
A B S T R A C T The renal responses to sympathetic nerve stimulation were studied in saline-expanded rats. The left kidney was partially denervated by crushing the left greater splanchnic nerve. Then the distal portion of the nerve was stimulated with square wave pulses of $0.5 \mathrm{~ms}$ duration, voltage twice threshold, and 1 or $2 \mathrm{~Hz}$ frequency while monitoring the compound action potential. Fibers with conduction speeds of $13-17 \mathrm{~m} \cdot \mathrm{s}^{-1}$ and of $0.7-1 \mathrm{~m} \cdot \mathrm{s}^{-1}$ were identified. Only stimulation of the latter appeared to produce changes in renal $\mathrm{Na}$ and water excretion. Whole kidney and individual nephron studies were performed alternating control and nerve stimulation periods. Nerve stimulation produced approximately a $25 \%$ reduction of the left kidney urine volume and sodium excretion. Glomerular filtration rate and renal plasma flow remained unchanged. Right kidney $\mathrm{Na}$ and water excretion, glomerular filtration rate, and renal plasma flow remained constant. In the left kidney, during nerve stimulation, the tubular fluid to plasma inulin concentration ratio increased significantly in the late proximal tubule.
\end{abstract}

We conclude that the antidiuresis and antinatriuresis seen during sympathetic nerve stimulation were caused by increased sodium and water reabsorption in the proximal tubule, probably mediated by the stimulation of slowly conducting unmyelinated fibers. These responses appeared to be unrelated to systemic or intrarenal hemodynamic changes.

\section{INTRODUCTION}

Although it is well known that the kidneys have an abundant nerve supply, its functional significance re-

Dr. Bello-Reuss was a Career Investigator Visiting Scientist of the American Heart Association. Dr. Gottschalk is a Career Investigator of the American Heart Association.

Received for publication 24 November 1975 and in revised form 26 January 1976. mains controversial. Only recently, Barajas and Müller have presented electron microscopic evidence that varicose regions of axons containing granular and agranular vesicles make contact with the basement membrane of proximal and distal tubular cells $(1,2)$. We have recently reported that the increases in urinary salt and water excretion which follow acute unilateral renal denervation in the rat occur in the absence of local or systemic circulatory effects, and are related to a decrease in absolute and fractional sodium and water reabsorption in the proximal tubule (3). Others have shown that acute surgical denervation or pharmacological blockade of the kidney's sympathetic supply results in a partial reversal of the antinatriuresis and a fall in proximal fractional reabsorption in dogs previously subjected to acute caval constriction (4). Also, when renal nerve activity was reduced after stimulation of the stellate ganglion, natriuresis and diuresis were observed without significant changes in glomerular filtration rate $(\mathrm{GFR})^{1}$ (5). Conversely, a decrease in sodium excretion in the absence of changes in renal plasma flow (RPF) and GFR has been reported in the dog after low frequency renal nerve stimulation (6). All of these results indicate a neural role in the control of renal tubular reabsorption of salt and water.

To investigate this further, the effects of stimulation of the distal part of a crushed splanchnic nerve were studied in the rat. Whole kidney and individual nephron studies were performed alternating control and stimulation periods. Our results show that splanchnic nerve stimulation produces reversible decreases in sodium and water excretion, which are the consequence of increased absolute and fractional reabsorption in the proximal tubule and which occur without change in RPF and GFR.

\footnotetext{
${ }^{1}$ Abbreviations used in this paper: GFR, glomerular filtration rate; RPF, renal plasma flow.
} 
TABLE I

Effects of Low Frequency Nerve Stimulation on Function of the Experimental and Contralateral Kidneys

\begin{tabular}{|c|c|c|c|c|c|c|c|c|}
\hline & \multicolumn{4}{|c|}{ Left kidney*, $n=6$} & \multicolumn{4}{|c|}{ Right kidney, $n=6$} \\
\hline & $\mathrm{C}_{1}$ & $\mathrm{~S}_{1}$ & $\mathrm{C}_{2}$ & $\mathrm{~S}_{2}$ & $\mathrm{C}_{1}$ & $S_{1}$ & $\mathrm{C}_{2}$ & $\mathrm{~S}_{2}$ \\
\hline \\
\hline$P$ & \multicolumn{2}{|c|}{ NS } & \multicolumn{2}{|c|}{ NS } & \multicolumn{2}{|c|}{ NS } & \multicolumn{2}{|c|}{ NS } \\
\hline $\begin{array}{l}\text { RPF, } \\
\mathrm{ml} \mathrm{min}^{-1} / 100 \mathrm{~g} \text { body wt }\end{array}$ & $1.87 \pm 0.18$ & $1.85 \pm 0.11$ & $1.72 \pm 0.13$ & $1.81 \pm 0.19$ & $1.93 \pm 0.19$ & $1.85 \pm 0.15$ & $1.75 \pm 0.16$ & $1.89 \pm 0.21$ \\
\hline$P$ & \multicolumn{2}{|c|}{ NS } & \multicolumn{2}{|c|}{ NS } & \multicolumn{2}{|c|}{ NS } & \multicolumn{2}{|c|}{ NS } \\
\hline $\begin{array}{l}\text { Urinary volume, } \\
\mu 1 \min ^{-1}\end{array}$ & $57.4 \pm 9.4$ & $43.0 \pm 5.5$ & $56.4 \pm 15.9$ & $42.2 \pm 13.5$ & $39.1 \pm 7.0$ & $33.2 \pm 3.2$ & $35.1 \pm 12.2$ & $41.3 \pm 15.2$ \\
\hline$P$ & \multicolumn{2}{|c|}{$<0.05$} & \multicolumn{2}{|c|}{$<0.02$} & \multicolumn{2}{|c|}{ NS } & \multicolumn{2}{|c|}{ NS } \\
\hline 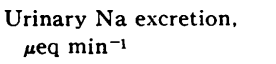 & $10.1 \pm 1.6$ & $7.4 \pm 0.7$ & $9.7 \pm 2.4$ & $7.2 \pm 1.9$ & $6.6 \pm 1.1$ & $5.8 \pm 0.5$ & $6.1 \pm 2.0$ & $7.0 \pm 2.3$ \\
\hline$P$ & \multicolumn{2}{|c|}{$<0.05$} & \multicolumn{2}{|c|}{$<0.01$} & \multicolumn{2}{|c|}{ NS } & \multicolumn{2}{|c|}{ NS } \\
\hline $\begin{array}{l}\text { Fractional } \mathrm{Na} \text { excretion. } \\
\quad \%\end{array}$ & $4.1 \pm 0.6$ & $2.9 \pm 0.4$ & $4.3 \pm 1.1$ & $2.9 \pm 0.9$ & $2.5 \pm 0.4$ & $2.2 \pm 0.2$ & $2.6 \pm 0.9$ & $2.9 \pm 1.1$ \\
\hline$P$ & \multicolumn{2}{|c|}{$<0.02$} & \multicolumn{2}{|c|}{$<0.005$} & \multicolumn{2}{|c|}{ NS } & \multicolumn{2}{|c|}{ NS } \\
\hline
\end{tabular}

Values are means \pm SEM. $P$ comparison by paired $t$ test of the results in the absence $\left(\mathrm{C}_{1}, \mathrm{C}_{2}\right)$ and during stimulation at $1 \mathrm{~Hz}\left(\mathrm{~S}_{1}\right)$ and $2 \mathrm{~Hz}\left(\mathrm{~S}_{2}\right)$.

Experimental kidney.

\section{METHODS}

Male Sprague-Dawley rats weighing $300-330 \mathrm{~g}$ were prepared for micropuncture as previously described (7). Catheters were placed into an external jugular vein for i.v. infusions, into the femoral artery for continuous measurement of arterial blood pressure, and into both ureters. The left greater splanchnic nerve was freed from connective tissue proximal to the celiac ganglion for a distance of about 10 $\mathrm{mm}$. Bipolar hook electrodes, made from 0.008 inch diameter platinum-iridium wire, were positioned around the freed portions of nerves for stimulation and recording. The electrodes and nerves were isolated from the surrounding tissues with a polyethylene sheet and covered with cotton saturated with mineral oil. A volume of $0.9 \% \mathrm{NaCl}$ solution equivalent to $10 \%$ of body weight was given i.v. over a period of approximately $30 \mathrm{~min}$ and was followed by a continuous infusion at $194 \mu \mathrm{l} / \mathrm{min}^{2}$ Inulin and p-amino-hippurate were added to the infusion for determination of GFR and RPF.

After ascertaining that the urinary flow rate was similar from both kidneys, the accessible upper portion of the left splanchnic nerve was crushed with forceps. After an equilibration period of $1 \mathrm{~h}$, whole kidney and single nephron measurements were performed alternating control $\left(\mathrm{C}_{1}, \mathrm{C}_{2}\right)$ and nerve stimulation $\left(S_{1}, S_{2}\right)$ periods of $45 \mathrm{~min}$ each. Nerve stimulation was carried out by means of a stimulator with an isolation unit. Square wave pulses of $0.5 \mathrm{~ms}$ duration, 3-16 V (twice threshold), and at repetition rates of $1 \mathrm{~Hz}\left(\mathrm{~S}_{1}\right)$ and $2 \mathrm{~Hz}\left(\mathrm{~S}_{2}\right)$ were used. The compound action potential evoked by these stimuli was recorded from the bipolar hook electrode located between the stimulating electrode and the kidney; after appropriate amplification, it was monitored on an oscilloscope.

${ }^{2} \mathrm{We}$ have found that renal denervation during volume expansion produces a diuretic and natriuretic response similar to that observed earlier in nonexpanded animals. BelloReuss, E., E. Pastoriza-Muñoz, and R. E. Colindres. 1976. Effects of acute unilateral renal denervation in saline-expanded rats. Clin. Res. 24: 35A.
Tubular fluid samples were collected as previously described (3) from three or more late proximal convolutions in each control and stimulation period. Blood samples were collected at the midpoint of each period from the femoral artery and by direct puncture of the renal vein with a 27 gauge needle.

Plasma and urine inulin concentrations were determined by the anthrone method (8). Inulin concentration in tubular fluid samples was measured by the method of Vurek and Pegram (9). Urine and plasma sodium concentrations were measured by flame photometry. $p$-amino-hippurate was measured by the method of Bratton and Marshall (10).

Single nephron GFR, fractional and absolute proximal reabsorption were calculated as previously stated (3). Statistical analyses were carried out by the Student $t$ test for paired groups. All results are expressed as means \pm SEM.

\section{RESULTS}

There were no significant changes in arterial blood pressure during the experiments; mean values were $112 \pm 2 \mathrm{~mm} \mathrm{Hg}$ during $\mathrm{C}_{1}$ and $110 \pm 4 \mathrm{~mm} \mathrm{Hg}$ at the end of $\mathrm{S}_{2}$. Arterial hematocrit also remained unchanged: $44.4 \pm 1.4 \% \quad\left(\mathrm{C}_{1}\right), 45.0 \pm 0.8 \% \quad\left(\mathrm{~S}_{1}\right), 44.5 \pm 1.5 \% \quad\left(\mathrm{C}_{2}\right)$, and $44.2 \pm 1.3 \%\left(\mathrm{~S}_{2}\right)$.

Whole kidney function. There was no significant difference between the urine flow of the left and right kidneys before denervation $(39.5 \pm 4.2$ and $40.7 \pm 5.1$ $\mu \mathrm{l} / \mathrm{min}$, respectively). As shown in Table $\mathrm{I}$, after crushing the left splanchnic nerve, $\left(C_{1}\right)$, urine output from the left kidney was greater than from the right kidney $(P<0.01)$. Nerve stimulation at $1 \mathrm{~Hz}\left(\mathrm{~S}_{1}\right)$ produced decreases of about $25 \%$ in urine flow and absolute and fractional $\mathrm{Na}$ excretion from the left kidney. After cessation of stimulation $\left(\mathrm{C}_{2}\right)$, both urinary volume and $\mathrm{Na}$ excretion returned to values indistinguishable from those in the previous control period. During the second stimulation period $\left(\mathrm{S}_{2}\right)$, a change of similar magnitude 
to that in $\mathrm{S}_{1}$ was observed. The mean of all urine flow rates from the left kidney in the absence of stimulation was $56.9 \pm 8.8 \mu 1 \mathrm{~min}^{-1}$ and during stimulation, 42.6 \pm 6.9 $\mu 1 \min ^{-1}(P<0.005)$. The mean $\mathrm{U}_{\mathrm{Na}} \mathrm{V}$ was $9.9 \pm 1.3 \mu \mathrm{eq}$ $\min ^{-1}$ and $7.3 \pm 0.9 \mu \mathrm{eq} \min ^{-1}(P<0.001)$ without and during stimulation, respectively.

There were no changes during the four periods in urinary volume or sodium excretion by the right kidney.

GFR, RPF, p-amino-hippurate extraction, and urinary sodium concentration remained unchanged throughout the four periods in both kidneys.

Micropuncture data. In all but one animal (Fig. 1) stimulation at $1 \mathrm{~Hz}\left(\mathrm{~S}_{1}\right)$ was followed by an increase in the $\mathrm{F} / \mathrm{P}_{\text {In }}$ ratio; mean values changed from $1.61 \pm$ 0.09 before stimulation to $1.92 \pm 0.12$ during stimulation $(P<0.05)$. After cessation of stimulation $\left(\mathrm{C}_{2}\right)$, the average $F / P_{I n}(1.53 \pm 0.13)$ was not different from that during the first control period; it increased to $2.02 \pm 0.14$ $(P<0.005)$ in the second stimulation $(2 \mathrm{~Hz})$ period. The mean of all control $\mathrm{F} / \mathrm{P}_{\mathrm{In}}$ determinations was $1.57 \pm$ 0.08 and of all during stimulation, $1.97 \pm 0.09 \quad(P<$ 0.001 ).

Low frequency stimulation did not significantly change single nephron GFR: $43 \pm 7 \quad\left(\mathrm{C}_{1}\right), 43 \pm 5 \quad\left(\mathrm{~S}_{1}\right), 42 \pm 5$

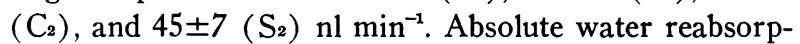
tion increased from $16 \pm 4$ in $C_{1}$ to $21 \pm 4 \mathrm{nl} \mathrm{min}{ }^{-1}$ ( $P<$ $0.05)$ during $S_{1}$, corresponding to a rise in fractional water reabsorption from $37 \pm 4$ to $47 \pm 4 \% \quad(P<0.005)$. After interruption of stimulation, water reabsorption fell to $14 \pm 3 \mathrm{nl} \mathrm{\operatorname {min } ^ { - 1 }}\left(\mathrm{C}_{2}\right)$; during $\mathrm{S}_{2}$, reabsorption in-

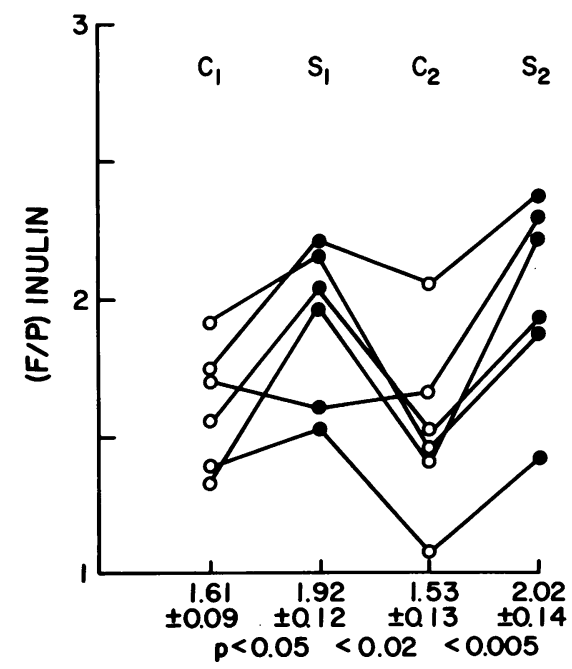

Figure 1 Effect of renal nerve stimulation on late proximal $F / P_{I n}$ after crushing the ipsilateral splanchnic nerve. Determinations were performed in the absence of stimulation $\left(\mathrm{C}_{1}, \mathrm{C}_{2}\right)$, and during stimulation at $1 \mathrm{~Hz}\left(\mathrm{~S}_{1}\right)$ and $2 \mathrm{~Hz}$ $\left(\mathrm{S}_{2}\right)$. Each individual point is the mean of two to four determinations. Lines join results in a single animal. Data on whole kidney function is presented in Table $\mathrm{I}$.
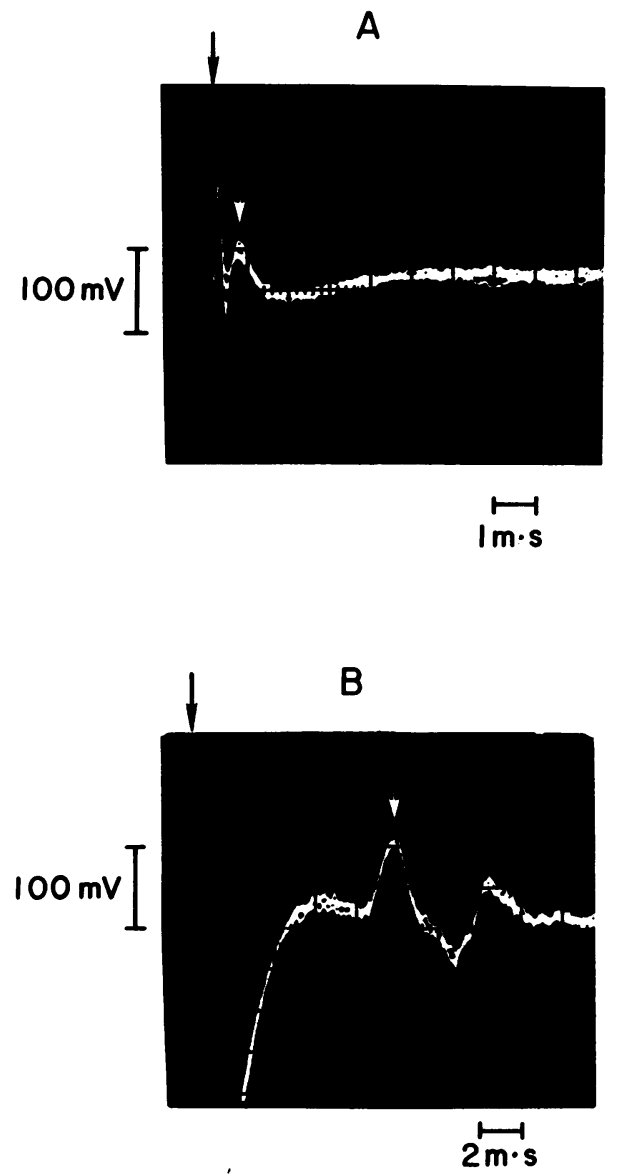

Figure 2 Typical records of compound action potentials. A: the white arrow indicates the deflection related to fibers with conducting velocity of $13-17 \mathrm{~m} \cdot \mathrm{s}^{-1}$. B : the white arrow indicates the component related to fibers conducting at $0.7-$ $1 \mathrm{~m} \cdot \mathrm{s}^{-1}$. Black arrows show stimulus artifacts; conduction distance $0.7 \mathrm{~cm}$. In $\mathrm{A}$, the stimulating pulses were $3 \mathrm{~V}, 0.1$ $\mathrm{ms}$; in $\mathrm{B}$, they were $15 \mathrm{~V}, 0.1 \mathrm{~ms}$. Note different time scales in $\mathrm{A}$ and $\mathrm{B}$. The component related to the more rapidly conducting fibers in $B$ is masked by the large stimulus artifact.

creased to $23 \pm 4 \mathrm{nl} \mathrm{min}{ }^{-1}(P<0.001)$. This corresponds to an increase of fractional water reabsorption from $32 \pm 6 \%\left(\mathrm{C}_{2}\right)$ to $49 \pm 4 \%\left(\mathrm{~S}_{2}\right)$.

In the one animal in which the $F / P_{\text {In }}$ ratio did not increase during the first stimulation period, sodium excretion was also inconsistently affected (7.3, 5.2 and 5.8 req $\min ^{-1}$ in $C_{1}, S_{1}$, and $C_{2}$, respectively). In $S_{2}$, the $\mathrm{F} / \mathrm{P}_{\mathrm{In}}$ ratio increased and sodium excretion decreased $\left(2.4 \mu \mathrm{eq} \mathrm{min}^{-1}\right)$ as occurred in both stimulation periods in all the other animals.

At times it was possible to identify two major components of the compound action potential: a shorter latency one consistent with fibers conducting at 13-17 $\mathrm{m} \cdot \mathrm{s}^{-1}$ with a lower threshold, and a deflection appearing at a latency consistent with $\mathrm{C}$ fiber conduction (0.7-1 
$\mathrm{m} \cdot \mathrm{s}^{-1}$ ) which had a higher threshold (Fig. 2). In two additional experiments, in an attempt to identify the fibers responsible for the change in sodium and water excretion, the splanchnic nerve was first stimulated at an intensity suprathreshold for the more rapidly conducting fibers but below that of the $\mathrm{C}$ fiber component, and then at a level twice the threshold for the slower $\mathrm{C}$ fibers. No changes in urine output or sodium excretion were observed at the lower intensity. However, with stimulation at the intensity exciting $\mathrm{C}$ fibers, urine volume decreased by $30 \%$ and sodium excretion by $32 \%$ (compare Table I).

\section{DISCUSSION}

This study confirms that low frequency electrical stimulation of the renal sympathetic nerves leads to an antidiuretic and antinatriuretic response in the absence of any changes in whole kidney GFR or RPF. Our micropuncture data demonstrate that this effect results from an increase in sodium and water reabsorption in the proximal tubule which occurs without significant modifications of either single nephron filtration rate or filtered load of sodium. It is of interest that in the one instance in which stimulation was associated with inconsistent changes in urinary sodium excretion, there was no change in proximal reabsorption. It is not apparent why there was a failure to respond to nerve stimulation this one time, but it may have resulted from either failure to excite the responsible nerve fibers or conduction block of the nerve distal to the stimulus application.

Whether the neural effect is "direct," i.e., an effect of the neurotransmitter or electrical events at the nerve endings on the transport mechanism, or "indirect" involving the renin-angiotensin, prostaglandin, kallikrein, or other humoral system cannot be determined from these studies. If a humoral substance was involved, it did not appear to gain access to the general circulation since the function of the opposite kidney was unaffected. Our earlier micropuncture studies (3) demonstrated that the neural effect did not appear to result from changes in the "physical factors." The renal nerves responsible for the effect appear to be the slowly conducting, unmyelinated $\mathrm{C}$ fibers.

As expected, the "denervation diuresis" caused by crushing the greater splanchnic nerve was smaller than that after application of phenol to the nerve fibers surrounding the renal artery. Complete denervation is apparently achieved with the latter technique, but visual observation shows that not all of the fibers come from the ipsilateral greater splanchnic nerve; hence, in the present study the denervation was incomplete.

We think it unlikely that the effect of expansion is mediated by renal nerve activity, since volume expansion and interruption of nerve impulses have additive effects on proximal salt and water transport. Our results also indicate that renal sympathetic tonic activity is present during extracellular volume expansion, consistent with the earlier observation that efferent renal nerve activity is reduced but not abolished after a $10 \%$ increase in blood volume (11).

\section{ACKNOWLEDGMENTS}

The technical assistance of $J$. Thomas Adkinson, and the secretarial assistance of Carolyn Custer are gratefully acknowledged. The authors are indebted to Dr. Edward $\mathrm{R}$. Perl for his valuable suggestions.

This study was supported by a grant-in-aid from the American Heart Association and by National Institute of Health grants, HL 02334 and NS 11132.

\section{REFERENCES}

1. Müller, J., and L. Barajas. 1972. Electron microscopic and histochemical evidence for a tubular innervation in the renal cortex of the monkey. J. Ultrastruct. Res. 41: 533-549.

2. Barajas, L., and J. Müller. 1973. The innervation of the juxtaglomerular apparatus and surrounding tubules: A quantitative analysis by serial section electron microscopy. J. Ultrastruct. Res. 43: 107-132.

3. Bello-Reuss, E., R. E. Colindres, E. Pastoriza-Muñoz, R. A. Mueller, and C. W. Gottschalk. 1975. Effects of acute unilateral renal denervation in the rat. J. Clin. Invest. 56: 208-217.

4. Slick, G. L., G. F. DiBona, and G. J. Kaloyanides. 1974. Renal sympathetic nerve activity in sodium retention of acute caval constriction. Am. J. Physiol. 226: 925932.

5. Takeuchi, J., N. Ohya, S. Sakai, H. Nakamura, T. Nohara, K. Hirasawa, and A. Shinoda. 1968. Nervous control of the renal tubular function. Jpn. Heart J. 9: 564-572.

6. Slick, G. L., A. J. Aguilera, E. J. Zambraskie, G. F. DiBona, and G. F. Kaloyanides. 1975. Renal neuroadrenergic transmission. Am. J. Physiol. 229: 60-65.

7. Gottschalk, C. W., and M. Mylle. 1956. Micropuncture study of pressures in proximal tubules and peritubular capillaries of the rat kidney and their relation to ureteral and venous pressures. Am. J. Physiol. 185: 430439.

8. Fuhr, J., J. Kaczmarczyk, and C.-D. Krüttgen. 1955. Eine einfache colorimetrische Methode zur Inulinbestimmung für Nieren-Clearance-Untersuchungen bei Stoffwechselgesunden und Diabetikern. Klin. Wochenschr. 33: 729-730.

9. Vurek, G. G., and S. E. Pegram. 1966. Fluorometric method for the determination of nanogram quantities of inulin. Anal. Biochem. 16: 409-419.

10. Bratton, A. C., and E. K. Marshall, Jr. 1939. A new coupling component for sulfanilamide determination. $J$. Biol. Chem. 128 : 537-550.

11. Clement, D. L., C. L. Pelletier, and J. T. Shepherd. 1972. Role of vagal afferents in the control of renal sympathetic nerve activity in the rabbit. Circ. Res. 31: 824-830. 